Fecha de recepción: marzo 2020 Fecha de aceptación: abril 2020 Versión final: junio 2020

\section{El uribismo y la forma de hacer política en Colombia: Discursos e imagen política}

Vannessa Morales Castro ${ }^{(1)}$

Resumen: El ascenso del uribismo a las esferas gubernamentales más altas en el 2002 marcó no sólo una ruptura en la tradicional política bipartidista colombiana, sino que además institucionalizó una nueva forma de discurso e imagen política, de la cual han hecho uso los candidatos que han ganado la presidencia desde 2002 en adelante. El presente trabajo se propone, entonces, analizar y comparar los discursos de campaña e imagen política, utilizados por Álvaro Uribe Vélez en 2002, por Juan Manuel Santos en 2010 y por el actual presidente Iván Duque en 2018.

Para poder realizar el ejercicio comparativo, se tomarán como fuentes de análisis los programas políticos empleados las campañas. De estos documentos se abordarán únicamente las propuestas relacionadas con la política de seguridad, en tanto que la continuidad de la misma ha sido la idea más explotada por los candidatos en las elecciones posteriores a 2002. A su vez, se seleccionarán los spots televisivos que aborden la misma dimensión y de esta forma identificar la repetición de conceptos, y finalmente la selección de algunos afiches publicitarios en los que sea clara la estrecha relación del candidato con Uribe. Este análisis permitirá dar cuenta de cómo el país ha asistido a la apropiación y legitimación de un discurso y una imagen política inaugurados en 2002.

Palabras clave: discurso de derecha - bipartidismo - regionalismo - uribismo.

[Resúmenes en inglés y portugués en las páginas 276-277]

(1) Es Doctoranda en Ciencias Sociales (FSOC-UBA), Magíster en Estudios Sociales Latinoamericanos (FSOC-UBA), Licenciada en Trabajo Social de la Universidad Nacional de Colombia. Participó en el Proyecto de Investigación Plurianual "Condiciones sociohistóricas de la violencia rural en América Latina, 1950s1990s". Actualmente forma parte del Ubacyt "Estado, élites y grupos económicos en América Latina 2000-2018” y el GT-CLACSO "Elites empresariales, Estados y dominación", dirigidos por la Dra. Inés Nercesian. 


\section{Introducción}

Las elecciones presidenciales de 2002 en Colombia dieron inicio a un periodo político y económico que se ha caracterizado por la derechización del discurso político, por la profundización del modelo económico neoliberal y por una importante reprimarización de la economía. Si bien Colombia nunca presenció gobiernos populistas que impulsaran políticas de industrialización, o gobiernos de signo nacional-popular que implementaran políticas distintas al proyecto neoliberal, la elección de Álvaro Uribe en 2002 no puede leerse solamente como la simple continuación del proyecto político y económico que históricamente se había implementado en el país. Por el contrario, el triunfo de Uribe debe interpretarse como un momento de reestructuración, en tanto que se profundizaron algunos de los rasgos de su formación económico-social, a la vez que se implementaron nuevas dinámicas y sobre todo nuevas formas políticas, las cuales se han extendido en el tiempo y de alguna manera han devenido imprescindibles en las campañas políticas.

Álvaro Uribe imprimió novedad en el escenario político-electoral por varios motivos entre los que podemos mencionar: su movimiento político distante de los partidos tradicionales, su discurso militarista, y el éxito permanente de su imagen. Al igual que otros países de la región como Uruguay, en Colombia el escenario político electoral había estado monopolizado por dos partidos centenarios, situación que se mantuvo hasta el 2002. Las presidencias de Colombia habían sido ocupadas de forma exclusiva por el Partido Liberal fundado en 1848 y el Partido Conservador fundado en 1849. Si bien Uribe había sido miembro del Partido Liberal, para las elecciones de 2002 se presentó con su propio movimiento político denominado Primero Colombia, con el cual salió ganador poniendo término a más de un siglo de bipartidismo.

La crisis de representación del bipartidismo se tradujo en una reconfiguración de las identidades políticas en la sociedad y el surgimiento de una identidad de derecha más clara (Nasi, 2007). La derechización del país se evidencia en los resultados de todas las elecciones posteriores a $2002^{1}$, es decir en los candidatos que han sido electos y lo que éstos representan, en la permanente imagen favorable de Uribe como representante de la derecha colombiana, y en la asimilación colectiva de un lenguaje inaugurado en 2002, el cual tiende a criminalizar tanto la izquierda armada como la izquierda legal ${ }^{2}$, situación que tiende a agravarse a medida que aumenta la polarización política del país.

En ese sentido, el triunfo electoral de Uribe no se puede entender sin tener en cuenta las transformaciones que han sufrido los partidos políticos, y el rol central que han adquirido los medios de comunicación en las campañas electorales y políticas. Los medios de comunicación han asumido el papel de mediación entre el electorado y el candidato que antes correspondía a los partidos políticos, los cuales han terminado siendo simples plataformas a disposición de los candidatos (Manin, 1995).

El nuevo rol de los partidos y la creciente importancia de los medios de comunicación se ha traducido en una mediatización de la imagen del candidato, pero también en una creciente personalización de la política ${ }^{3}$, es decir en la variación del voto en función del candidato y no tanto por el programa o por el partido político (Rebolledo, 2017). Esta situación se refuerza en las elecciones presidenciales, las cuales han devenido en las más importantes $^{4}$, y su resultado termina dando forma al conjunto de la vida política. Los me- 
dios de comunicación especialmente la televisión y la radio, han favorecido y potenciado este proceso de personalización de la política, en la medida que son los que se encargan de visibilizar a los candidatos.

Para Rahat y Sheafer (2007), se pueden mencionar tres tipos de personalización: la institucional que alude a los mecanismos institucionales que permiten hacer énfasis en el político individual; la de medios de comunicación que alude al énfasis de los medios de comunicación en el político, no así en su colectivo político; y finalmente la del comportamiento electoral que se refiere al impacto de la imagen del político en la decisión del voto. La personalización tiene algunos componentes como: supremacía de líder político por encima del partido, exaltación de las características de su personalidad y el uso político de algunos aspectos de su vida personal. Para lograr el efecto deseado en el electorado, tanto medios como candidato, crean una estrategia (comunicación política), tendiente a influir en la percepción de este grupo.

El tipo de personalización va a depender del sistema político en el que se presenta y para el caso colombiano que es presidencialista, el líder político tiende a adquirir una mayor prominencia sobre la colectividad (Pinto Velazco, 2013). Una de las consecuencias de este proceso de personalización, es la popularización que se encuentra más ligado a las redes sociales y que por ejemplo se traduce en la capacidad del líder para definir o redefinir la identidad política que lideran. La popularización per se no atrae votos, ya que el candidato también debe presentar un posicionamiento frente a un contexto político determinado, tarea de la cual se encargan los equipos de marketing político ${ }^{5}$. El marketing político tiene algunos niveles estratégicos dentro de los cuales se puede mencionar: estrategia política (propuesta política o el qué decir), estrategia comunicacional (discurso político) y estrategia publicitaria (imagen) (Rebolledo, 2007).

En el presente texto se abordará especialmente la estrategia política, la cual se define en función del posicionamiento político, es decir el tema elegido que será su sello distintivo en la campaña y también el contexto internacional en el cual se enmarca.

A su vez la Estrategia Publicitaria, es decir la imagen transmitida remite a la dimensión estética, la dimensión personal y también la simbología elegida para llevar a cabo la campaña (García Beaudoux y D'Adamo, 2006). Para la construcción de la imagen política se hace uso de diferentes medios como apariciones televisivas, declaraciones públicas y spots publicitarios, los cuales han devenido en la herramienta más importante de campaña ya que el electorado obtiene información sustancial y logra llegar a poblaciones heterogéneas. Asimismo, los spots sirven para generar interés en el candidato, construir el reconocimiento de su nombre, redefinir su imagen, reforzar el apoyo, influir sobre los indecisos entre otros. Sin embargo, la forma como se presenta el candidato, también depende de la escala de valores del electorado, es decir que la imagen es una construcción conjunta (Baeza, 2012). Las formas de presentar a un candidato son múltiples, sin embargo, la herramienta más utilizada por su alcance e impacto, es el spot televisivo en tanto que permite construir una sensación falsa de relación personal, que no es otra cosa que una relación virtual donde no interfiere la figura del partido político (Cheresky, 2007).

El éxito logrado por Uribe, en lo que concierne a la construcción de su exitosa imagen política, radicó en la exaltación de sus características y rasgos personales ${ }^{6}$, pero también en la estrategia política de su campaña en 2002 y 2006, por no mencionar el uso permanente del 
marketing gubernamental durante los 8 años de su gobierno. Por un lado, Uribe continuó siendo una figura central de la política colombiana, logrando obtener una imagen favorable permanente por encima del $60 \%$ en casi dos décadas, es decir que logró mantenerse como un líder político de referencia y con altísimos índices de popularidad. Por otro lado, Juan Manuel Santos (2010) e Iván Duque Márquez (2018), han hecho uso de esta popularidad en sus campañas políticas: ya sea transmitiendo la seguridad de continuidad de la política uribista, ya sea mostrándose lo más cercano posible a Álvaro Uribe.

Para poder develar los elementos que se instalaron en las campañas políticas de los candidatos presidenciales elegidos después del 2002, el presente texto se dividirá en cuatro momentos: en la primera parte se reconstruirá la estrategia política de las campañas de Uribe en 2002 y 2006. Para este propósito se examinarán algunos spots de campaña y programas de gobierno. En la segunda y tercera parte se examinarán los mismos elementos, pero con las campañas de Juan Manuel Santos en 2010 e Iván Duque en 2018. En la cuarta parte se intentará dar cuenta de los elementos discursivos y de imagen política, que han tenido continuidad en las campañas y que garantizaron de alguna manera la victoria de estos candidatos.

\section{Las campañas presidenciales de Álvaro Uribe en 2002 y 2006}

\section{Contexto y estrategia política 2002}

El contexto en el que se desarrollaron las elecciones presidenciales de 2002 se caracterizó principalmente por un sentimiento de impotencia frente a los índices económicos que había dejado la administración de Andrés Pastrana (1998-2002). En 1999 el país vivió una crisis económica que se tradujo en aumento del desempleo que llegó al 20\%, en la liquidación de varias entidades financieras y en la implementación de un plan de ajuste con el FMI (Portafolio, 2009).

Además de la difícil situación económica, el gobierno de Pastrana terminó su mandato con un proceso de paz fallido ${ }^{7}$ con la guerrilla de las Fuerzas Armadas Revolucionarias de Colombia (FARC). Si bien no era el primer proceso de paz que había fracasado con dicha guerrilla, las condiciones bajo las cuales Pastrana adelantó este proceso fueron muy criticadas $^{8}$, especialmente por la zona de distensión, que consistió en el despeje militar de los municipios San Vicente del Caguán, Uribe, Macarena, Vistahermosa y Mesetas en los departamentos del Meta y Caquetá. ${ }^{9}$ Tanto para los historiadores Marco Palacios (2012) y Fernán González (2014), el fracaso de dicho proceso y la fórmula de mano dura, le permitieron a Uribe no sólo ganar las elecciones, sino también gozar de una alta popularidad durante sus dos mandatos, donde vale la pena aclarar, hubo también una estrategia permanente de marketing gubernamental (Daza Beltrán, 2007).

A la situación económica y al fallido proceso de paz, se debe sumar el impacto del 11 de septiembre y la reconfiguración de la política de seguridad, así como de la nueva terminología empleada para caracterizar a los grupos guerrilleros como grupos terroristas. Esta nueva retórica de guerra se tradujo a nivel local en el reemplazo de ciertos términos 
para definir el conflicto como, por ejemplo: grupos beligerantes por grupos narcoterroristas o rendición incondicional y derrota militar en lugar de acuerdo de paz o salida negociada al conflicto. La política de seguridad del gobierno se tradujo en un enaltecimiento de las fuerzas armadas, las cuales también vivieron un proceso de reconfiguración de la mano del Plan Colombia ${ }^{10}$ financiado por Estados Unidos, así como en un incremento significativo del accionar paramilitar ${ }^{11}$.

En el programa de gobierno presentado en la primera campaña de Uribe, denominado Manifiesto Democrático, los 100 puntos de Álvaro Uribe Vélez ${ }^{12}$, son dos las propuestas más importantes que van de la mano con el momento político: el Estado Comunitario y la Seguridad Democrática.

El Estado Comunitario consistía en un importante recorte presupuestal, austeridad administrativa y cero politiquería y corrupción. "La Presidencia será austera para dar ejemplo. Gastará menos en burocracia para invertir más, por ejemplo, en pequeña empresa.” (Manifiesto Democrático, 2002, p. 2).

Mientras que la seguridad democrática consistiría en el enaltecimiento de las fuerzas armadas y policiales, en el incremento del pie de fuerza, en la aprobación de un estatuto antiterrorista para facilitar las acciones militares y en la creación de una red de cooperación ciudadana sin paramilitarismo, pero en coordinación con la fuerza pública. La Seguridad tendría como acompañante el adjetivo Democrática, en tanto que defendería a cualquier ciudadano de la violencia de cualquier actor armado.

Concertar con transportadores y taxistas para vincularlos a la seguridad de calles y carreteras. Cada carretera tendrá un coronel del Ejército o de la Policía responsable de su seguridad. El lunes será el "Día de la Recompensa" que pagará el Gobierno a los ciudadanos que en la semana anterior hubieran ayudado a la fuerza pública a evitar un acto terrorista y capturar al responsable. A liberar un secuestrado y capturar al secuestrador. Se respetará la reserva de identidad y se exigirá visto bueno de las autoridades competentes (Ibíd, 2002, p. 5).

En una entrevista realizada por el noticiero $C M \&^{13}$, Uribe afirmó sobre la política económica y su nexo con la propuesta de seguridad:

Lo primero que necesita la política económica es que los inversionistas recuperen la confianza inversionista en el país. Esa confianza nace del orden público y de la estabilidad en las reglas de juego. El país no puede invitar a los inversionistas para que vengan y los secuestren, el país no puede invitar a las empresas a invertir en carbón con una exención tributaria y a los dos años la desmontan.

Sobre su propuesta de seguridad:

Siempre he hablado de la necesidad de no llevar a Colombia al polo del diálogo claudicante ni al otro extremo de la guerra arrasada. He dicho que, con 
autoridad democrática, eficaz, con suficiente fuerza pública, con decisión presidencial, con un presidente como primer soldado de la patria, con un millón de ciudadanos apoyando a la fuerza pública transparentemente, ese día empieza el final de la guerrilla, la desintegración de los paramilitares y la recuperación de los derechos humanos.

El énfasis en la seguridad, estuvo acompañada de la palabra patria y de la palabra autoridad. De esta manera la estrategia comunicacional, intentó poner en juego estos elementos, tratando de combinarlos con una reducción de la simbología representativa del país, esto es: el slogan "Mano firme corazón grande", la bandera tricolor y accesorios de los trajes típicos de ciertas regiones del país, especialmente la de la región caribe y la de la región cafetera colombiana, apelando a su origen paisa. ${ }^{14}$ Tanto en lo discursivo como en su imagen Uribe se presentó como un hombre providencial, firme, generoso y dispuesto a sacrificarse por el país (Richard, 2008).

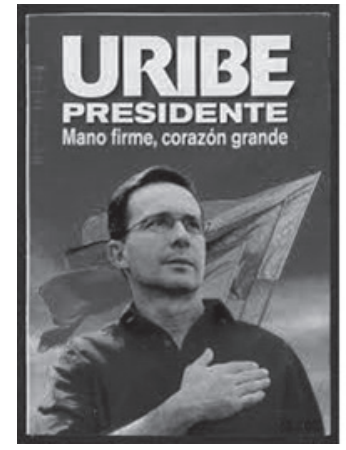

Figura 1. Mano firme corazón grande. Fuente: González, D.R. (2019). Nos quieren devolver al 2002. Disponible en: https://blogs.elespectador.com/ actualidad/el-cuento/nos-quieren-devolver-al-2002

Como se muestra en la Figura 1, la estrategia comunicativa y utilizada en 2002 por Uribe se diferenciaba radicalmente de la utilizada por su principal oponente Horacio Serpa del tradicional Partido Liberal. En el afiche de Serpa se reivindican dos elementos tradicionales como el color rojo del Partido Liberal y el traje con corbata propio de un político tradicional, elementos que no se encuentran en el afiche de Uribe, donde no aparece ninguna filiación política aparente, y tampoco se muestra como un político tradicional de traje y corbata.

En ese sentido Uribe prefirió mostrarse como un candidato por fuera de los partidos políticos y más bien como un ciudadano del común o por lo menos como un político alternativo, imagen que sumada a la novedosa propuesta de mano firme en materia de seguridad, le permitió ganar en las elecciones presidenciales de 2002 en primera vuelta ${ }^{15}{ }^{16} \mathrm{con}$ un $54 \%$ de votos, mientras que Serpa solo obtuvo el 32\%. 


\section{Novedades en la campaña 2006}

En 2005 Uribe decidió proponer una reforma constitucional para aprobar la reelección inmediata y así darle continuidad a su mandato. En ese sentido la campaña de reelección estuvo orientada a ratificar en las urnas la alta popularidad que había logrado en su primer mandato. La reelección fue un elemento novedoso, que sin embargo fue eliminado en 2015, pues este mecanismo pareció ir en contravía de la tradición y cultura política del país.

Sobre la segunda campaña en 2006 hubo otra novedad además de la reelección: Uribe se presentó por su propio partido llamado Partido de la U (Partido Social de la Unidad Nacional), creado en el 2005 bajo el liderazgo de la facción uribista del Partido Liberal, donde tuvo un protagonismo importante Juan Manuel Santos. La creación de su propio partido y la proliferación de otros partidos aliados, ${ }^{17}$ le permitió consolidar su presencia mayoritaria en el senado y en la Cámara, a pesar que muchos congresistas de la coalición uribista se vieran investigados y encontrados culpables por nexos con el paramilitarismo, ${ }^{18}$ en lo que se denominó el escándalo de la parapolítica (Roa Gutierrez, 2007).

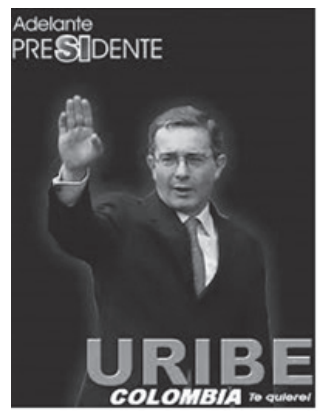

Figura 2. Adelante Presidente. Fuente: Richard, E. y Llano, A. (2017). La historia sin fin (al feliz) de la paz en Colombia (o La crisis como estrategia de comunicación de gobierno) Contratexto (28), pp. 147-171. Disponible en: http://revistas.ulima.edu.pe/ index.php/contratexto/article/view/1539

El slogan de esta segunda campaña fue el de "Adelante Presidente". A diferencia de la primera, ésta buscó confirmar a través del voto las políticas que venía impulsando el gobierno y reafirmar su popularidad. En ese sentido la campaña se centró en dos ejes: recordar las acciones del primer mandato, en especial la política de seguridad y en hacer ver como un retroceso su interrupción; y en darle la posibilidad a cada ciudadano de diseñar en una página web, su propio afiche de apoyo ${ }^{19}$ (Daza Beltrán, 2007). Además de los afiches autogestionados, los spots de campaña se basaron en pequeñas historias de gente del común que manifestaba su apoyo a Uribe:

“-Yo he estado con el café toda la vida, desde pequeño la ilusión mía sería mejorar, porque el café es el que mueve Colombia. -

-En el corazón de éste hombre late con fuerza el sentimiento colombiano- 
- En Colombia la U soy yo-

-Orgullosamente Uribista. Partido de la U unidos como debe ser-"20.

O en otros que recordaban los logros del gobierno en materia de seguridad

El silencio nos estaba matando... hasta que un día juntos elegimos a un gobernante que nos hizo ver que no nos podían matar a todos y el país volvió a nacer y pronto se hizo fuerte y empezó a gritar su orgullo y a correr por sus tierras y a soñar y a trabajar, trabajar y trabajar, porque la unión de una nación hizo la fuerza. El partido de la $\mathrm{U}$ ahora celebra que ahora sea posible reelegir a un gran país. Partido de la U”21.

Sobre las elecciones de 2006 y los ciudadanos que votaron la continuación de Uribe en la presidencia, se debe volver a mencionar la importancia de los partidos políticos de la coalición uribista, muchos de los cuales surgieron después del proceso de paz que Uribe adelantó con los paramilitares, a quienes se les concedió el perdón y olvido por sus actividades narcotraficantes, la promesa de no extradición y la opción de la participación política electoral. De los espacios que antes eran controlados por la guerrilla y que después pasaron a ser controlados por los paramilitares, surgió una parte importante de electores que fueron el pilar de la reelección. Otra parte de su electorado provenía de aquellos ilusionados por una falsa recuperación del control territorial por parte del Estado y el restablecimiento del monopolio de la fuerza (Palacios, 2012). Los resultados de las elecciones de 2006, ratificaron la popularidad de Uribe que obtuvo el $62 \%$, mientras que el candidato opositor Carlos Gaviria $^{22}$ logró solamente el $22 \%$.

La popularidad de Uribe al terminar su mandato superaba el 70\%, pero ante la negativa de la Corte Constitucional para aprobar la reelección indefinida, el uribismo tuvo que reformular su proyecto de sucesión presidencial.

\section{La campaña presidencial de Juan Manuel Santos 2010}

\section{Contexto y Estrategia política}

Juan Manuel Santos provenía de una familia política de tradición liberal. Su tío abuelo había sido presidente entre 1938 y 1942 y su familia había estado vinculada de forma permanente en política. De hecho, su primo Francisco Santos había fungido como vicepresidente de los dos gobiernos de Uribe, y el propio Juan Manuel había estado al frente de diferentes carteras ministeriales tanto en gobiernos de signo conservador, como en gobiernos de signo liberal, e incluso en el gobierno de Uribe como Ministro de Defensa. Durante su gestión como Ministro de Defensa bajo el gobierno de Uribe, Santos logró propinar fuertes golpes a la guerrilla como por ejemplo el bombardeo en el que murió Luis Edgar Devia Silva más conocido como Raúl Reyes ${ }^{23}$ en 2008, o Víctor Julio Suárez Rojas, más conocido como el Mono Jojoy ${ }^{24}$ en ese mismo año. Si bien Santos había sido el prota- 
gonista de los mayores golpes a las FARC hasta ese momento, su campaña política se basó en mostrarse ante el electorado como el sucesor legítimo de Uribe. En ese sentido y como se verá más adelante, su victoria fue más el resultado de su aparente cercanía con Uribe y su membresía al Partido de la U, que su gestión como ministro o su trayectoria política.

Con respecto a las propuestas de campaña, Santos presentó un documento denominado Buen Gobierno para la Prosperidad Democrática. 110 puntos para lograrla ${ }^{25}$. Entre los puntos más destacados de su programa Santos planteaba:

Decidiremos quién liderará nuestro país y en qué dirección avanzaremos. Decidiremos si queremos honrar el mejor gobierno en nuestro país en mucho tiempo, el gobierno del Presidente Álvaro Uribe, o si enterramos su legado. Decidiremos si queremos seguir avanzando, o si nos arriesgamos a retroceder (Buen Gobierno para la prosperidad democrática, 2010, p. 2).

Sobre la política de seguridad, el mismo documento afirmaba:

Derrotaremos al terrorismo, terminaremos el conflicto y construiremos la paz. Mantendremos una presión incesante sobre los violentos, organizados en bandas criminales, grupos guerrilleros y terroristas. No les dejaremos más opción que la rendición, la reinserción y la aceptación de la Constitución Política de Colombia. Mantendremos la exitosa política del Presidente Álvaro Uribe Vélez, que combinó la mano tendida y el pulso firme (Ibíd, 2010, p. 55).

En un principio, Juan Manuel Santos desarrolló su campaña política apartado del uribismo, hecho que cambió ante los resultados de las encuestas que proyectaban un empate técnico con el candidato opositor del Partido Verde ${ }^{26}$, Antanas Mockus ${ }^{27}$. Ante la posibilidad de perder las elecciones, Santos modificó la estrategia de su campaña el 30 de abril de $2010^{28}$. Este cambio consistió en hacer énfasis explícito en su pertenencia al Partido de la $U$, en su cercanía con Uribe y en su preocupación por la seguridad y el empleo (Ochoa Lozano, 2011).

Esta nueva orientación se hizo evidente en los nuevos spots televisivos, en los que se encuentran algunas continuidades discursivas con el gobierno anterior, y otras novedades propias de la coyuntura del momento; el desempleo. Entre las continuidades discursivas se encuentra la política de seguridad y el no volver atrás como sinónimo de no cambiar la política. Esta estrategia ya había sido utilizada en 2006 por Uribe, que promovió la idea de su no reelección como un retroceso y un riesgo para los avances en materia de seguridad. De esta manera, algunos spots apelaron al miedo de retroceder y mostrar a Santos como el candidato que daría continuidad a las políticas del gobierno anterior (Carmona, 2011):

Yo no quiero volver a sentir ese miedo. No quiero preguntarme si escuché un trueno o una bomba, si el cilindro de gas que va en ese camión es para cocinar o para hacer un atentado. Si eso es un carro viejo o un carro bomba. No quiero salir a pasear con mi familia y preguntarme si ese retén es el del ejército o de la guerrilla, si el trancón es por un accidente o por una pesca milagrosa. Yo no 
quiero volver a sentir ese miedo, no quiero. No quiero que vuelvan a aumentar los índices de secuestro y que por miedo no vuelvan al país los inversionistas, ni los artistas y los eventos internacionales. ¿Que nos quedemos sin clientes y que cierren negocios y usted? De eso se trata esta decisión, de tomar el riesgo de echar para atrás o de tener la seguridad de seguir avanzando porque sin seguridad no puede haber prosperidad ${ }^{29}$.

Hace ocho años soñábamos con recuperar el territorio, la confianza inversionista y la seguridad, ahora soñamos con un país con trabajo, trabajo y más trabajo para todos y juntos lo vamos a lograr. Este treinta de mayo vota Juan Manuel presidente ${ }^{30}$.

Trabajar, trabajar y trabajar. Con este pensamiento hace ocho años un líder cambió a Colombia. Ahora los uribistas vamos a poner a trabajar a todo el país, porque si hay trabajo hay platica, la economía se mueve y el país avanza. -Hemos logrado mucho pero queremos lograr muchísimo más. - Este 30 de mayo vamos con Juan Manuel, porque votar por Juan Manuel, es votar por un país con trabajo, Juan Manuel presidente. Partido de la $\mathrm{U}^{31}$.

Con respecto a la imagen empleada por Santos en sus afiches publicitarios, antes del cambio no se reivindicaban los colores del Partido de la $\mathrm{U}$, sino que se utilizaba un color naranja en el que se perdía la idea de adscripción al partido de Uribe y en consecuencia no se transmitía la seguridad de continuidad de la política uribista. Por otra parte, tampoco retomaba ningún elemento de los afiches de Uribe, ya fuera la bandera tricolor o la mano en el pecho como síntesis del slogan "Mano firme corazón grande". Sin embargo, con el cambio de estrategia que se señaló anteriormente, el nuevo afiche mostró a Santos como el candidato del Partido de la U y en consecuencia el candidato de Uribe.

Según los resultados de los sondeos de voto realizados por el Gallup ltda $a^{32}$, los porcentajes de favorabilidad entre marzo y abril del 2010, forzaron este cambio en la estrategia de campaña, ante el vertiginoso aumento de intención de voto de Mockus.

La nueva campaña de Santos tuvo slogan "El gobierno de la Prosperidad Democrática", una frase con la que pretendía mostrar un cambio con respecto a su antecesor en términos de una nueva etapa que atendería nuevos problemas sociales, pero conservando los elementos esenciales del uribismo y así no perder el respaldo del electorado. Sin embargo, la fórmula vicepresidencial de Santos no fue un cuadro o político del uribismo sino Angelino Garzón, expresidente de la Central Unitaria de Trabajadores (CUT) y vicepresidente de la Unión Patriótica ${ }^{33}$.

Aunque las diferencias entre Santos y Uribe no eran tan palpables en ese momento, el nombramiento de la fórmula vicepresidencial, el empleo de nuevos términos, y la estrategia de acercarse al Uribismo a menos de un mes de la primera vuelta, ya marcaban ciertas diferencias que se harían públicas en 2012 con el anuncio de un nuevo acuerdo de paz con las FARC.

El spot en el que se presentó la fórmula vicepresidencial empleaba otros conceptos como los del texto del siguiente spot: 
-Nosotros vamos a luchar frontalmente-

-Contra el desempleo, la pobreza y la desigualdad social-

-Crear más empleos y mejore salarios-

-Empleos formales, con todos los beneficios-

-Vamos a mejorar la cobertura y la calidad en la educación. -

-Porque es el mejor camino para reducir las desigualdades y conseguir trabajo.-

- Vamos a mejorar el sistema de salud. -

-Para que todos los colombianos sean bien atendidos. Unidos como debe ser. Vota Unidos ${ }^{34}$.

Si bien la campaña de Santos y de todos los partidos que decidieron apoyarlo, se hizo bajo la sombra de la figura de Uribe y las políticas de su gobierno (Pinto Velazco, 2013), hubo un cambio sustancial en la política implementada por Santos cuando decidió hacer un acuerdo de paz con las FARC. Esta decisión le costó el apoyo de Uribe, que siempre había planteado una política de exterminio militar antes que una salida dialogada al conflicto. Ante el respaldo del partido de la U a los acuerdos de Paz con las FARC, Uribe decidió fundar nuevamente su propio partido en 2013, con el nombre Centro Democrático, usando como imagen una réplica del que fuera su afiche de campaña en 2002.

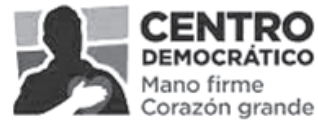

Figura 3. Centro Democrático. Fuente: Revista Semana (2018). Disponible en: https://www.semana.com/eleccionescongreso-2018/noticias/partido-centro-democratico-listacandidatos-al-senado-y-camara-elecciones-2018-557995

La enemistad con Uribe por poco le cuesta la reelección a Santos, quién se enfrentó con Iván Zuluaga que había sido Ministro de Hacienda de Uribe (2007-2010). Los resultados de la primera vuelta dieron por ganador al candidato uribista con un $29 \%$ de votos contra un $25 \%$ de Santos. Pero si Santos ya no contaba con el apoyo de Uribe, ¿cómo explicar su reelección en 2014? Al respecto Rivas (2016) señala que el contexto en el que se desarrollaron las elecciones, hizo que todos los candidatos tuvieran que tratar el tema de la paz. En ese sentido los medios de comunicación ayudaron a establecer la paz como el tema central de la elección con enunciados alusivos al rumbo de la paz.

Con el tema de la paz como eje central, Santos logró revertir el triunfo del uribismo centrando su campaña en la continuidad de la paz y en contra de la guerra con el slogan "con paz haremos más". Su triunfo se explica por el apoyo que recibió del voto de opinión y sectores de izquierda, quienes en realidad votaron por el mal menor ${ }^{35}$. Estos votos garantizaron su victoria, pero no lograron revertir de forma contundente el ascenso uribismo, pues la diferencia entre ambos candidatos fue de sólo trescientos mil votos.

El costo para Santos de su decisión de alejarse de Uribe fue tener una opinión desfavorable por encima del $80 \%$ al terminar su mandato en $2018 .{ }^{36}$ Aunque no se analizará en profundidad la campaña de Zuluaga en 2014, vale la pena resaltar que su estrategia fue la misma empleada por Santos en 2010: Ser el verdadero heredero de la política de Uribe. Uno de los 
spots en los que aparecen imágenes de Zuluaga, mientras Uribe presenta a su partido y al candidato, muestra de forma clara el uso de esta estrategia. "Nuestro partido es el Centro Democrático, nuestro candidato Óscar Iván Zuluaga, compañero de todas las batallas, no pasajero de ocasión. Zuluaga Presidente"37.

La férrea oposición que Uribe le hizo al gobierno de Santos le permitió volver a capitalizar un importante caudal electoral y reafirmar su imagen favorable, hecho que quedó plasmado en tres victorias contundentes: el plebiscito para refrendar los acuerdos de Paz con las FARC $^{38}$, obtener la mayor votación en la historia de Colombia como senador en 2018 (casi un millón de votos), y hacer ganar a su candidato Iván Duque en las elecciones presidenciales de ese mismo año. Además de estos resultados en las elecciones presidenciales de 2018, se debe mencionar el debilitamiento del Partido de la U (partido oficial del gobierno Santos), el cual pasó de ser la primera fuerza política en el senado en 2010 y 2014, a ser la quinta después de las elecciones parlamentarias de 2018.

\section{La campaña presidencial de Iván Duque 2018}

\section{Contexto y Estrategia política}

Durante el segundo mandato de Santos (2014-2018), Uribe logró consolidar su partido como el partido de oposición, hecho que quedó reflejado en las elecciones legislativas de 2018, en las cuales el Centro Democrático logró ser mayoría en el senado. Al igual que las elecciones del 2010 y el 2014, Uribe decidió lanzar nuevamente su propio candidato: el senador Iván Duque. La campaña del uribismo se centró en la crítica a los acuerdos de paz, la situación política de Venezuela y el reciclaje de algunos elementos utilizados por Uribe en su primera campaña, especialmente en el slogan y la imagen.

La oposición a Santos tomó como eje discursivo, una fuerte crítica al proceso de paz que se adelantó con las FARC. Frente los Acuerdos de Paz, el uribismo manifestó en repetidas ocasiones su oposición a los mismos, alegando impunidad y otra serie de vicios. Esta postura fue consignada en las propuestas de la campaña de Duque ${ }^{39}$ :

Nos afecta ver que la justicia premia a quienes han cometido los peores crímenes de nuestra historia, bajo el abuso de la palabra "paz" (...) Tendremos la férrea voluntad de actuar de manera decidida contra la impunidad, asegurando que los máximos responsables de crímenes de lesa humanidad no puedan aspirar a cargos de elección popular, luego de un proceso de desmovilización, desarme y reinserción, sin haber cumplido una pena efectiva y proporcional. (203 propuestas, 2018, p. 2).

Sobre la política de seguridad, Duque retoma propuestas y conceptos del gobierno Uribe como por ejemplo "Integraremos y reordenaremos los aparatos de inteligencia sobre la base de la cooperación ciudadana y el uso de tecnologías de punta” (Idíd, 2018, p. 7).

En los spots de campaña: 
Soy Iván Duque y soy como tú que quiere tener mejores oportunidades de trabajo y que no nos suban más los impuestos. Soy como tú que quiere seguridad y que no tengamos impunidad. Soy Iván Duque y soy como tú, orgullosamente colombiano que quiere darlo todo por este país. Este 11 de marzo pide el tarjetón de la gran consulta por Colombia y marca Iván Duque Centro Democrático. Duque es el que es ${ }^{40}$.

El slogan "Duque es el que es", hace mención a que es el elegido por Uribe, lo que en otras palabras se traduce en que es el candidato que efectivamente dará continuidad a su política y en el que Uribe depositó toda su confianza. En ese sentido y al igual que en la campaña de Santos, una buena parte de la campaña de Duque se construyó de nuevo a la sombra de la figura de Uribe, esta vez con el slogan "Yo voto por el que diga Uribe".

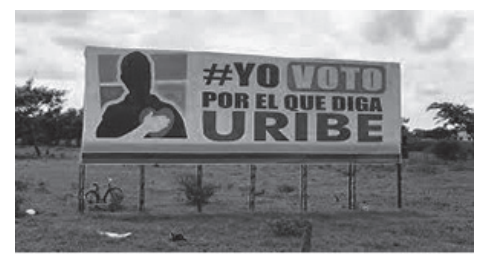

Figura 4. Yo voto por el que diga Uribe. Fuente: Revista Semana (2017). "Yo voto por el que diga Uribe":

Polémica por valla en Montería. Disponible en: https:// www.semana.com/nacion/articulo/yo-voto-por-elque-diga-uribe-polemica-por-valla-publicitaria-enmonteria/531814

En un debate político organizado por la emisora La FM ${ }^{41}$, los candidatos tuvieron que responder las preguntas de lo que el moderador denominó "El Quiz Uribista”. De este modo se les preguntó a los candidatos: ¿Que tanto conoce al presidente Álvaro Uribe de 1 a 10 ? ¿Cuántos pares de crocs tiene el presidente Álvaro Uribe? ¿Nombre de los nietos del expresidente Álvaro Uribe? ¿Cuál es el nombre del caballo del expresidente Álvaro Uribe? En uno de los spots de campaña, Duque expone su política económica, la cual guarda una íntima relación con la planteada en el programa de campaña de Uribe del 2002. Allí se juega a emular la terminología del líder político y de hecho al final del spot aparece Duque junto a Uribe y ambos repiten el slogan "Mano firme corazón grande", y ambos emulan la mano el pecho, que como se vio, fue una de las imágenes más usadas por Uribe en su campaña de 2002 y de 2006. "Necesitamos recuperar nuestra economía, cero derroches, un Estado austero y eficiente que nos permita bajar impuestos, subir salarios. -(Aparece Uribe) Vote por Colombia, Iván Duque: transparencia juvenil, firmeza, preparación.Mano firme, corazón grande" 42 .

El otro eje sobre el que se construyó la campaña y se relaciona directamente con el contexto internacional fue Venezuela. Desde la oposición frente a los acuerdos de paz, el Uribismo logró generar miedo a los proyectos alternativos al orden neoliberal: primero argumentando que se le había entregado el país a las FARC, y segundo promoviendo la idea que cualquier gobierno alternativo desembocaría en una situación similar a la del 
vecino país. Paradójicamente Gustavo Petro ${ }^{43}$, el segundo candidato más votado representaba una propuesta alternativa. En este eje, el uribismo logró articular discursivamente el miedo a ser como Venezuela ante la posibilidad de elegir otra propuesta política.

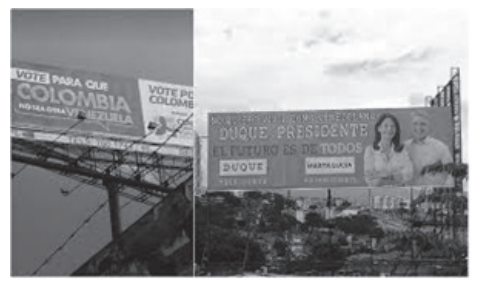

Figura 5. No queremos ser como Venezuela. Fuente: Pulzo (2018). Tildan de xenófobas vallas en que aparece Duque; su campaña niega la autoría. Disponible en: https://www.pulzo.com/elecciones-2018/vallas-ivanduque-contra-venezolanos-bucaramanga-PP482998

Si bien los resultados de las elecciones fueron novedosos en tanto que, por primera vez en la historia política del país, un candidato de centro izquierda lograba obtener 8 millones de votos, también lo fueron porque ganó un candidato sin mayor carrera política, salvo ser senador por el Centro Democrático entre 2014 y 2017. Es decir que en estas elecciones no sólo triunfó el que dijo Álvaro Uribe, sino la vuelta de un discurso invariable que parece ser el preferido por el electorado que lo ha votado desde el 2002.

\section{Conclusiones}

Si bien hace falta analizar de forma más detallada el rol que han jugado los medios de comunicación en la exitosa personalización de la política en Colombia, hay algunos aspectos que podemos señalar frente a lo que ha sido la construcción de la imagen de Uribe y de ahí en adelante la de los candidatos/presidentes hasta la actualidad. Efectivamente el país asiste desde hace algunos años a un fenómeno de personalización donde la figura de la personalización sigue siendo Álvaro Uribe.

Si la personalización se define como el voto por el individuo más allá de la colectividad, lo que se ha votado en las últimas elecciones presidenciales ha sido la figura de Uribe; no así los candidatos y su trayectoria política o personal y mucho menos a los partidos políticos. En ese sentido pareciera que el país ha asistido a la personalización de la política, bajo la figura de Álvaro Uribe, al tiempo que se asiste a una despersonalización de los candidatos, ya que la definición del voto se hace en función de su cercanía con el líder político y no por su propia individualidad o partido político.

El liderazgo de Álvaro Uribe ha logrado trascender al Partido de la U, y si llegara el caso seguramente trascendería al Centro Democrático. En ese sentido la personalización en Colombia ha profundizado la crisis de representación de los partidos políticos. Si bien el texto no abordó las características de la personalidad de Uribe, en la última campaña 
presidencial (2018), incluso se llevó a cabo el denominado "test uribista", que consistió en la formulación de una serie de preguntas de índole personal, las cuales cada candidato debería responder, y de esta forma dejarle en claro a la audiencia cuál candidato era más cercano a Uribe. Algunas de las preguntas - ¿Cuántos pares de crocs tiene Uribe? y ¿Cuánto calza? - por parte de los medios de comunicación, ayudan a profundizar la personalización de la política y para el caso concreto, la prolongación de la figura de Uribe en el escenario electoral, a pesar de que éste no sea candidato.

En ese sentido y retomando la propuesta de Rahat y Sheafer (2007), podemos afirmar que en Colombia se ha desarrollado una personalización de los medios de comunicación, que se combina con la personalización del comportamiento electoral. Los medios de comunicación se han encargado de reforzar la imagen de Uribe, pero también el electorado ha escogido en reiteradas ocasiones su discurso o en todo caso aquellos candidatos que lo encarnan.

El mérito de Uribe en 2002 consistió en poder leer de forma acertada la coyuntura política con respecto al proceso de paz con las FARC. La forma de capitalizar las expectativas frustradas de una parte importante de la sociedad, fue con la fórmula novedosa de un tratamiento militar y de mano dura. A su vez, detrás del éxito de este discurso se encuentra la crisis de los partidos tradicionales, los cuales no pudieron volver a ganar las elecciones presidenciales. Por el contrario, después de 2002 surgieron una multiplicidad de partidos fugaces aliados a Uribe, los cuales han logrado capturar una parte mayoritaria de los votos tanto a nivel regional como nacional. A medida que se ha fortalecido la figura de Uribe, se han debilitado los partidos políticos y ha aumentado la polarización política.

Como se vio, la primera campaña de Juan Manuel Santos tuvo que utilizar la imagen de Uribe para asegurarse el éxito electoral. Este acercamiento implicó un juego de palabras que remplazó seguridad democrática por prosperidad democrática, una reafirmación de la pertenencia al partido de la U y la exhibición de una relación cercana con Uribe. A su vez, su ruptura con el líder dada su decisión de adelantar un acuerdo de paz y un dialogo político con las FARC, en vez de un tratamiento militar, le costó la pérdida de su imagen favorable y el debilitamiento de su partido. A su vez el triunfo de Duque, hace más evidente el fenómeno de personalización, pues el candidato no contaba con ninguna trayectoria política visible antes de ser el "heredero" de Uribe, y de hecho su campaña explotó esta cercanía entre el candidato y el líder político.

No se puede afirmar que la estrategia política diseñada en cada elección ha sido la misma, porque de hecho la propia coyuntura ha hecho que las propuestas y la agenda sufran algunas modificaciones, aunque el uribismo en cabeza de sus candidatos ha sabido seguir explotando algunos de los sentimientos que en su momento generó el primer gobierno de Uribe en 2002. Como se planteó al comienzo del texto, el electorado tiene una escala de valores y el candidato que más se ajuste a esta escala, es el elegido. ¿Cuáles son esos valores? Para Carlos Daza Beltrán (2007), uno de los sentimientos más explotados por el uribismo ha sido el miedo, de allí se entiende por qué la sobrevaloración de la seguridad. Otro de los sentimientos, ha sido el odio a las FARC, sentimiento que ha logrado superar en anhelo de la paz. De esta manera En el 2002 se explotó el miedo al fortalecimiento de las FARC, en el 2010 miedo de volver al pasado donde las FARC era una guerrilla fuerte y en 2018 el miedo a ser como Venezuela, como consecuencia de la firma de los acuerdos de 
paz con esta guerrilla. La oferta para curar el miedo está en brindar más seguridad, por eso ofrecer la seguridad democrática sigue siendo un atractivo para el electorado.

El país ha asistido a una reconfiguración de las formas de hacer campañas electorales, tanto a nivel discursivo con la sobredimensión que se le da a la seguridad, como de representación política dada la debilidad de las estructuras partidarias (tanto las viejas como las nuevas), y a nivel de la imagen dada la personalización de Álvaro Uribe Vélez, y la necesidad de mostrar una estrecha cercanía con él, incluso que se es lo mismo. Estos tres factores han estado presentes en estas últimas dos décadas y en parte ayudan a explicar las trasformaciones que ha vivido el escenario político electoral en los últimos años.

\section{Notas}

1. Salvo la elección de 2014 en la que ganó Santos con muy poca diferencia, con una cifra de abstención de casi el $60 \%$, y con la consecuencia de terminar su mandato con tan solo el 16\% de aprobación, luego de la firma de los acuerdos de paz.

2. Para Carlo Nasi (2007), la derechización es evidente en lo que respecta al nuevo trato que se les dio a las guerrillas, que perdieron su estatus de grupos beligerantes, y por el contrario se extendió al conjunto de su gobierno y a una parte importante de la sociedad. Para el autor, esto responde a tres factores: el fracaso de los diálogos del Caguán, el establecimiento de un ranking delictivo en el que el primer lugar lo ocupan los delitos cometidos por la guerrilla como el secuestro y la promesa de derrota de la guerrilla.

3. En este texto se retoma la definición de Rebolledo (2017) para quién personalización es el proceso mediante el cual el el líder político adquiere una mayor visibilidad respecto a su partido, se resaltan los rasgos más sobresalientes de su personalidad y la presencia de aspectos de su vida privada como políticos. La visibilidad puede ser promovida desde el ámbito institucional, desde los medios de comunicación y por el electorado.

4. Para Perry Anderson (2003), la implementación de políticas neoliberales, ha tenido como correlato, una fuerte concentración del poder en el poder ejecutivo. Presidencialización no es lo mismo que personalización, en tanto que el primero implica un aumento del poder en torno a un cargo institucional, que en este caso se centra en el cargo presidencial, que solamente al adquirir una mayor visibilidad.

5. El Marketing Político, alude a una serie de herramientas utilizadas a lo largo de una campaña electoral. Sobre Marketing Político ver Costa Bonino (1994).

6. Las características personales devienen en políticas en tanto que influyen en la imagen que el elector se hace del candidato y por lo tanto tienen un sentido político. De esta forma en la personalidad del candidato quedan incorporados elementos tanto de la vida pública (capacidad de liderazgo, gestión, trayectoria política, etc), como de la vida privada (humor, vida familiar, sexualidad, etc) (Rico, 2009).

7. Para profundizar sobre la cronología del proceso de paz de Andrés Pastrana véase: https://www.semana.com/nacion/articulo/la-paz-de-pastrana-asi-fue-el-frustrado-capitulo-del-caguan/622639 
8. Para Carlo Nasi (2007), las críticas al proceso de paz, únicamente se centraron en los errores cometidos por la guerrilla. De esta manera se construyó un relato histórico en donde no se hizo una evaluación de los errores del gobierno de Pastrana. Este relato de culpabilización de las FARC, fue el utilizado para alimentar el discurso de odio hacia la guerrilla, y en consecuencia legitimar el accionar y discurso del gobierno de Uribe.

9. En total se calcula un área de 42.000 kilómetros despejados y ocupados por las FARC. 10. Fue un conjunto de medidas legales y presupuestarias del gobierno de Estados Unidos para que distintas agencias de ese mismo país, adelantaran acciones enmarcadas en la guerra contra las drogas, sin embargo, como lo señala Palacios (2012), la implementación del Plan Colombia se tradujo en una combinación de guerra contra el narcotráfico y contra las guerrillas, ya que las mismas fueron incluidas en los listados de grupos terroristas

11. Véase el informe Grupo de Memoria Histórica. (2013). ¡Basta ya! Colombia: Memorias de guerra y dignidad.

12. Véase en https://alvarouribevelez.com.co/contenido-general/primera-campana-2-2/

13. Véase https://www.youtube.com/watch?v=aj7A0wdJe3s

14. Denominación empleada en Colombia para referirse a oriundos de la zona cafetera (Departamentos de Antioquia, Quindío y Risaralda).

15. Véase Richard (2008). Álvaro Uribe: la comunicación por la imagen. Principios del Marketing Político.

16. Para que haya un escenario de segunda vuelta, el candidato más votado debe obtener la mitad más uno de todos los votos.

17. Entre los partidos aliados del uribismo surgió Cambio Radical (1998), Convergencia Ciudadana (1997), Alas Equipo Colombia (2006), Colombia Democrática (1985), Colombia Viva (2003).

18. El fenómeno paramilitar en Colombia nació de la alianza entre narcotraficantes, latifundistas, políticos y prácticas de la política contrainsurgente (Palacios, 2012). Entre sus tareas estaba limpiar las zonas rurales "simpatizantes" de la guerrilla y asesinar potenciales aliados de la guerrilla. Para profundizar sobre el paramilitarismo véase el informe del Centro de Memoria Histórica sobre Paramilitarismo (2018).

19. Los afiches se diseñaban en la página www.adelantepresidente.com

20. Véase: https://www.youtube.com/watch?v=sraxXPjAdh8\&list=PLzpapITwQtIXz0e7h 7pbcvBTV_NewBzc\&index $=18$

21. Véase: https://www.youtube.com/watch?v=0LqQGvKtzWw\&list=PLzpapITwQtIXz0e 7h7pbcvBTV_NewBzc\&index=23

22. Fue Magistrado de la Corte Constitucional y político por el partido Polo Democrático Alternativo.

23. Era el comandante del Bloque Sur y miembro del secretariado de las FARC, es decir de la cúpula militar de la organización guerrillera.

24. Era el comandante del Bloque Oriental y miembro del secretariado de las FARC.

25. Véase en: http://static.iris.net.co/semana/upload/documents/Doc-2089_201086.pdf

26. El Partido Verde es un partido de centro, pacifista y ambientalistas creado en 2009.

27. Político y filósofo colombiano. 
28. Véase Ochoa Lozano (2011). Análisis de la Estrategia de Campaña Presidencial de Juan Manuel Santos, desde mayo de 2009 hasta junio de 2010.

29. Véase: https://www.youtube.com/watch?v=K8RDospNwRU\&list=PLzpapITwQtIUE_ 81h1Y6I2Vu66ytk_-3Z\&index $=34$

30. Véase: https://www.youtube.com/watch?v=K8RDospNwRU\&list=PLzpapITwQtIUE_ 81h1Y6I2Vu66ytk_-3Z\&index=34

31. Véase: https://www.youtube.com/watch?v=S_tgWXPZpHI\&list=PLzpapITwQtIUE_8 1h1Y6I2Vu66ytk_-3Z\&index=25

32. Véase: https://redescolombia.files.wordpress.com/2010/03/43e916be7674ff10a216b78 8f9f7f9f0.pdf

33. La Unión Patriótica (UP) fue un partido político fundado en 1984, el cual surgió de los diálogos de paz adelantados entre la administración de Belisario Betancur y la guerrilla de las FARC. La propuesta era permitir la participación política de los guerrilleros.

34. Véase: https://www.youtube.com/watch?v=aEUSbkFEsi4

35. Véase: Rodríguez (2014). Álvaro Uribe y Juan Manuel Santos: ¿una misma derecha?

36. Véase: https://www.elespectador.com/noticias/politica/aprobacion-del-presidentesantos-cae-al-14-segun-primera-encuesta-yanhaas-de-2018-articulo-733818

37. Véase: https://www.youtube.com/watch? $\mathrm{v}=\mathrm{SaOwQ} 4 \mathrm{zEClA}$

38. Para entender el contexto en el que se desarrolló el plebiscito y sus resultados véase Morales Castro (2016).

39. Véase: https://www.youtube.com/watch?v=bGlVeETH9M8

40. Véase: https://www.youtube.com/watch?v=bGlVeETH9M8

41. Véase: https://www.lafm.com.co/politica/que-tanto-saben-de-alvaro-uribe-losprecandidatos-del-centro-democratico

42. Véase: https://www.youtube.com/watch?v=_EBke-bCEZY

43. Político colombiano de centro izquierda. Fue guerrillero del M-19. Participó en la redacción de la constitución de 1990, fue senador de la república y alcalde de Bogotá entre 2010 y 2013.

\section{Bibliografía}

Anderson, P. (1999). Historia y lecciones del neoliberalismo. Revista del Centro de Estudios del Trabajo 25.

Aprobación del presidente Santos cae al 14 \%, según primera encuesta Yanhaas de 2018. (17 de enero de 2018). El Espectador. Disponible en: https://www.elespectador.com/noticias/ politica/aprobacion-del-presidente-santos-cae-al-14-segun-primera-encuesta-yanhaasde-2018-articulo-733818

Baeza, N. S. (2012). Cómo se construyó el candidato: Un estudio de caso sobre Imagen Política [en línea]. Trabajo final de grado. Universidad Nacional de La Plata. Disponible en: http://www.memoria.fahce.unlp.edu.ar/tesis/te.836/te.836.pdf 
Centro Nacional de Memoria Histórica (2013). ¡Basta ya! Colombia: Memorias de guerra y dignidad. Bogotá: Centro de Memoria Histórica. Disponible en: http://www.centrodememoriahistorica.gov.co/micrositios/informeGeneral/descargas.html

Centro Nacional de Memoria Histórica (2018). Paramilitarismo. Balance de la contribución del CNMH al esclarecimiento histórico, Bogotá, CNMH. Disponible en: http://www.centrodememoriahistorica.gov.co/micrositios/balances-jep/descargas/balance-paramilitarismo. pdf

Cheresky, I. (2007). Argentina: la política que viene. Umbrales de América del Sur 1(3), pp. 111-135.

Costa Bonino, L. (1994). Manual de marketing político. Montevideo: Editorial Fin de Siglo.

Daza Beltrán, C. (2010). Análisis de las estrategias de marketing político de Álvaro Uribe Vélez durante sus campañas electorales de 2002 y 2006 y durante el ejercicio de su gobierno presidencial en Colombia. Tesis de Maestría. Pontificia Universidad Javeriana.

de la Calle, M. R. (2017). La personalización de la política: una propuesta de definición para su estudio sistemático. Revista de comunicación 16, pp. 147-176.

D’Adamo, O. J., y Beaudoux, V. G. (2006). La construcción de la agenda de temas en una campaña electoral y su impacto en los votantes. Psicología política (33), pp. 7-24.

Elección Presidencial 2002. (2010, febrero 04). Noticiero CM\&. (Archivo de video). Disponible en: https://www.youtube.com/watch?v=aj7A0wdJe3s

González González, F. E. (2014). Poder y violencia en Colombia. Bogotá: Editorial Pontificia Universidad Javeriana.

La paz de Pastrana: así fue el frustrado capítulo del Caguán. (7 de septiembre de 2019). Revista Semana. Disponible en: https://www.semana.com/nacion/articulo/la-paz-depastrana-asi-fue-el-frustrado-capitulo-del-caguan/622639

Manin, B. (1997). The principles of representative government. Cambridge: Cambridge University Press.

Morales Castro, V. (2016). Reflexiones en torno a los resultados del plebiscito por la paz en Colombia. Cuadernos de Coyuntura. Disponible en: http://coyuntura.sociales.uba.ar/ reflexiones-en-torno-a-los-resultados-del-plebiscito-por-la-paz/

Nasi, C. (2007). Derechización 'a la colombiana' en tiempos confusos: un ensayo especulativo. Colombia internacional (66), pp. 162-183. Disponible en: http://www.scielo.org. co/pdf/rci/n66/n66a10.pdf

Ochoa Lozano, M. P. (s/f). Análisis de la estrategia de campaña presidencial de Juan Manuel Santos, desde mayo de 2009 hasta junio de 2010 (Doctoral dissertation, Universidad del Rosario).

Palacios, R. M. (2012). Violencia pública en Colombia: 1958-2010. Bogotá: Fondo de cultura económica.

Partido Centro Democrático (2018, febrero 23). Iván Duque Presidente candidato presidencial 2018-2022. (Archivo de video). Disponible en: https://www.youtube.com/ watch? $=$ bGlVeETH9M8

Partido Centro Democrático. (Centro Democrático Comunidad Oficial). (2014, abril 30). Oscar Iván Zuluaga Presidente. (Archivo de video). Disponible en: https://www.youtube. com/watch?v=SaOwQ4zEClA 
Partido Centro Democrático. (Sangre azul). (2018, agosto 18). Las mentiras de Iván Duquey Álvaro Uribe (Archivo de video). Disponible en: https://www.youtube.com/watch?v=S_tg WXPZpHI\&list=PLzpapITwQtIUE_81h1Y6I2Vu66ytk_-3Z\&index=25

Partido de la U. (2010). Buen gobierno para la prosperidad democrática. 110 iniciativas para lograrla. Disponible en: http://static.iris.net.co/semana/upload/documents/Doc2089_201086.pdf

Partido de la U. (Comunicación y Política Ciudadana). (2016, septiembre 12). En Colombia soy yo cafetero (Archivo de Video) Disponible en: https://www.youtube.com/watch?v=s raxXPjAdh8\&list=PLzpapITwQtIXz0e7-h7pbcvBTV_NewBzc\&index=18

Partido de la U. (Comunicación y Política Ciudadana). (2016, octubre 24). Yo no quiero volver a sentir ese miedo. (Archivo de video). Disponible en: https://www.youtube.com/ watch?v=K8RDospNwRU\&list=PLzpapITwQtIUE_81h1Y6I2Vu66ytk_-3Z\&index=34

Partido de la U. (Comunicación y Política Ciudadana). (2016, octubre 24). Spot 13. (Archivo de video). Disponible en: https://www.youtube.com/watch?v=U2lQD6TPqGk\&list=PL zpapITwQtIUE_81h1Y6I2Vu66ytk_-3Z\&index=27

Partido de la U. (Comunicación y Política Ciudadana). (2016, octubre 24). Spot 11. (Archivo de video). Disponible en: https://www.youtube.com/watch?v=S_tgWXPZpHI\&list=PLz papITwQtIUE_81h1Y6I2Vu66ytk_-3Z\&index=25

Pinto Velazco, M. C. (2013). La personalización de la política en Colombia: análisis de las elecciones presidenciales de 2010. Tesis de Maestría. Universidad Complutense de Madrid.

Portafolio. (24 de julio de 2009). Colombia entre 199 y 2008. Disponible en: https://www. portafolio.co/economia/finanzas/colombia-1990-2008-308848.

Rahat, G. y Sheafer, T. (2007). The Personalization(s) of Politics: Israel, 1949-2003. Political Communication (24), pp. 65-80.

Rebolledo, M. (2017). La personalización de la política: una propuesta de definición para su estudio sistemático. Revista de comunicación, (16), pp. 147-176.

Richard, E. (2008). Álvaro Uribe: la comunicación por la imagen. Principios de marketing político. Ópera (8), pp. 73-100. Disponible en: https://revistas.uexternado.edu.co/index. php/opera/article/download/760/720/

Rico, G. (2009). Líderes políticos, opinión pública y comportamiento electoral en España. Madrid: CIS.

Roa Gutiérrez, E. (2007). Guía práctica para entender el escándalo de la para-política. Revista Semana. Disponible en: https://www.semana.com/on-line/articulo/guia-practica-paraentender-escandalo-para-politica/84455-3

Rodríguez, G. P. (2014). Álvaro Uribe y Juan Manuel Santos:; una misma derecha?. Nueva Sociedad, (254), 84-99. Disponible en: https://nuso.org/articulo/alvaro-uribe-y-juanmanuel-santos-una-misma-derecha/.

Abstract: Uribismo's rise to power to the most important governmental spheres in 2002 marked not only an interruption to the Colombian traditional bipartisanship, but also led to new forms of political speech and opinion, employed by elected candidates from 2002 
on. This work intends to analyze and compare both the campaign speeches and political opinion used by Alvaro Uribe Velez in 2002, by Juan Manuel Santos in 2010 and by the current president Iván Duque in 2018. This comparison will allow to explain how Colombia has witnessed the appropriation and legitimization of a right-wing speech by a part of the citizenship.

Keywords: Right - wing speech - bipartisanship - regionalism - uribismo.

Resumo: A ascensão do Uribismo às mais altas esferas governamentais em 2002 marcou não apenas uma quebra na política bipartidária tradicional da Colômbia, mas também institucionalizou uma nova forma de discurso e imagem política, que os candidatos que ganharam fizeram uso de a presidência de $2002 \mathrm{em}$ diante. O presente trabalho é proposto para analisar e comparar os discursos da campanha e a imagem política, utilizados por Álvaro Uribe Vélez em 2002, por Juan Manuel Santos em 2010 e pelo atual presidente Iván Duque (2018). Essa comparação nos permitirá explicar como o país ajudou na apropriação e legitimação de um discurso correto pelos cidadãos.

Palavras-chave: discurso da direita - bipartidarismo - regionalismo - uribismo.

[Las traducciones de los abstracts fueron supervisadas por el autor de cada artículo] 